\title{
Pedagogical Innovation among University Faculty
}

\author{
Karen E. Boden \\ Department of Education, Azusa Pacific University, Azusa, CA, United States \\ Email:kboden@apu.edu
}

How to cite this paper: Boden, K. E. (2019). Pedagogical Innovation among University Faculty. Creative Education, 10, 848-861.

https://doi.org/10.4236/ce.2019.105063

Received: March 19, 2019

Accepted: May 11, 2019

Published: May 14, 2019

Copyright (c) 2019 by author(s) and Scientific Research Publishing Inc. This work is licensed under the Creative Commons Attribution-NonCommercial International License (CC BY-NC 4.0). http://creativecommons.org/licenses/by-nc/4.0/ (c) (7) \&) Open Access

\begin{abstract}
Faculty often emphasize research compared with teaching in their work. However, some faculty endeavor to be excellent teachers by innovating pedagogy to enhance student learning. This qualitative study focused on developing a theory to describe faculty's innovative process. The theory defined as Reciprocal Engagement includes one category: Practice. Three sub-categories emerged-Cycle of Innovation, Cycle of Feedback, and Gradation of Innovation-which describe the process of innovation. Cycle of Innovation indicates an accumulation of innovation over the course of a faculty's career. Cycle of Feedback suggests the academic and social engagement between faculty and students. Gradation of Innovation describes the three levels of pedagogical innovation.
\end{abstract}

\section{Keywords}

Pedagogical Innovation, Research Universities, Faculty Development

\section{Introduction}

Teaching has become an atrophied skill among some faculty compared with innovation in research. With such focus placed on research, how does a professor perform two critical responsibilities effectively-teaching and research-as part of his or her faculty work? As shown by funding indicators (Capaldi, Lombardi, Abbey, \& Craig, 2010), the process of innovation in research in higher education occupies much faculty time and attention. Among faculty at many colleges and universities, the perceived preeminent role of research overshadows the noteworthy responsibility of teaching (Blackburn \& Lawrence, 2003; Schuster \& Finkelstein, 2008). Many colleges and universities boast excellent faculty who devote both time and energy to teaching for the purposes of student achievement (Astin, 1997; Kuh, Kinzie, Schuh, \& Whitt, 2010). 
Little research has been conducted on the process that faculty undertake to innovate their teaching which suggests using a grounded theory approach when no theory exists to explain a process (Creswell, 2017). When faculty undergo innovation and transformation of teaching practices to become exemplary educators, they experience a change process that a grounded theory approach may discover and examine to develop a theory to describe this social process (Charmaz, 2014; Creswell, 2017). A research study investigating the experiences of those professors who conduct research and develop expertise in teaching would provide awareness and insight to improve faculty work. In addition, the choice to study the innovative process of faculty who excel at research, which is rewarded well, is to illuminate the practices of those who value excellent teaching. As a result, this study may inform faculty and the broader higher education community to foster an optimal environment for innovative teaching to occur; ultimately, this will enhance the learning environment for students and faculty alike.

The purpose of this grounded theory study is to explore the process by which tenured/senior faculty members innovate their teaching and also demonstrate excellence in research. The first section of this paper defines and discusses innovation; whether an original idea or previously employed concept, innovation becomes the impetus for change. The next section outlines the research methodology that was used to conduct a qualitative study of faculty who innovate and transform their teaching methods. This section specifies participant criteria and selection, data collection, and data analysis. The third section addresses the overall theory of Reciprocal Engagement with one emerging theme of practice. Participants' practice focuses on and develops further their teaching practice in order to enhance and support student learning. Practice explores and discusses the three subcategories-Cycle of Innovation, Cycle of Feedback, and Gradation of Innovation-that describe the recurring innovative process results in the product of innovation. Further, the final section of this paper suggests possible implications for fostering practice. The theory of Reciprocal Engagement provides an opportunity for faculty members and faculty development departments to engage in improving pedagogical innovation to enhance student learning.

\section{Innovation}

The focus of this study is to discover the process that faculty undertake to innovate their teaching methods and strategies to develop into excellent teachers. Throughout the history of higher education, colleges and universities as well as faculty have undergone transformation to adapt to the changing realities of society. In the 21st century, population diversity and the market demands of a global knowledge economy increase the certainty that faculty may need to adapt to this changing dynamic. Those faculty members who innovate their teaching to meet the challenge of 21st century changes may well succeed in this evolving dynamic of higher education. 
To guide this study, innovation is defined as implementing original or previously known ideas, methods, or instruments to a given situation as a mechanism, impetus, and stimulus for the process of change with the intent to improve an organization's performance, processes, or services (Furst-Bowe \& Bauer, 2007; Kontoghiorghes et al., 2005; White \& Glickman, 2007). Teaching innovations typically include pedagogical practices of active learning, experimentation, collaboration, technology application, and authentic assessment (Bok, 2008; Breslow, 2010; Kezar, 2009; Zemsky, 2009; Zhang, 2010). Moreover, innovation in higher education, often defined by technology (Richards, 2004), includes additional topics such as student access and equity, learning assessments, and academic accountability (Bok, 2008; Kezar, 2009; Zemsky, 2009). In the context of this study, innovation may include the implementation of known pedagogical practices to enhance or change current teaching strategies. Faculty members who innovate include the idea of transforming themselves as well as their environment or circumstances.

\section{Methodology}

A grounded theory approach was used to interview over the course of one academic year nine full-time tenured professors at eight RU/VH institutions: Georgetown University; Penn State University; University of California-Berkeley, Los Angeles, San Diego, Santa Barbara, and Santa Cruz; and Yale. Through Facebook, a social network, RU/VH institutions alumni were contacted and asked to suggest participants who met the established criterion for innovative faculty. All participants had the following basic characteristics: full-time, tenured professor, mid-career or more, and a PhD educational level. A broad scope of academic disciplines-economics, education, geology, geography, history, physics, sociology, and theater-was represented. To protect the identity of participants, male pronouns were used and gender-neutral names were assigned to each of seven male and two female faculty members.

\subsection{Data Collection}

Faculty award systems tend to be murky because the selection process may be obscure, be overtly symbolic, or reward teaching performance (McAlpine \& Harris, 2002; Menges, 1996; Sorcinelli \& Davis, 1996; Van Note Chism, 2006). However, some faculty award systems utilize both student and alumni input for selection (Lowman, 1996; Menges, 1996; Van Note Chism, 2006). Research has indicated that students and alumni specify similar characteristics of effective teaching as faculty and administrators (Centra, 1996; Van Note Chism, 2006). Rather than use institutional recommendations, an alternative method was developed that asked alumni from the $131 \mathrm{RU} / \mathrm{VH}$ research universities to nominate professors who demonstrated innovative teaching while the alumni were undergraduate students. Participants were asked to provide demographic information to verify fulfillment of selective criteria as stipulated for the purposes of this study. 
Participants who met the stated criteria were contacted through telephone calls and/or emails and given a written description of the research project, a list of interview questions, and a consent form. After the sampling process and criteria were determined, nine people agreed to participate in this study. I traveled to each participant's campus to conduct semi-structured interviews that included open-ended questions to gather in-depth and detailed data on the process of becoming innovative. Data included participants' detailed accounts of their experiences. Questions and an interview protocol were used to ensure consistency among participants.

\subsection{Data Analysis}

All interviews were digitally recorded and transcribed. Extensive field notes were taken throughout the data collection process to ensure rich, thick descriptions regarding participants. During campus visits to conduct interviews, I observed classroom teaching to further investigate participants' accounts of innovation. Classroom observations enabled first-hand examination of each participant's setting and, to some degree prolonged engagement for added data analysis reliability. Constant comparative analysis of data continued throughout the data collection and analysis. Data were constantly reviewed, compared to initial themes, and coded until no additional themes were added. Additional interviews were conducted to provide member checking to ensure saturation and triangulation of data. Saturation was reached when no new themes emerged from data collection therefore ensuring data validation and trustworthiness. Data were compared to determine similarities and differences within a participant's interview and between various participants' interviews and accounts of incidents.

\section{Reciprocal Engagement}

One theme emerged from the analysis of participant interviews-Practice. This theme led to the development of a theory called Reciprocal Engagement. Practice identifies the innovative process as three subcategories-Cycle of Innovation, Cycle of Feedback, and Gradation of Innovation. Cycle of Innovation indicates a continuous development of pedagogical change resulting in a cumulative effect over years of teaching. Input from students through a Cycle of Feedback provides faculty with information to innovate. Faculty evaluate students' learning through reading their affect, evaluating their questions, and responding to faculty evaluations. Gradation of Innovation distinguishes degrees of innovation-adoption, modification, and creation.

Although Practice suggests a sequential approach, Reciprocal Engagement does not specify a structurally linear progression, but rather a cyclic innovative process that recurs: fueling upon one another, creating momentum and reinforcement. The findings suggest the importance for faculty to build on their pedagogical strategies and practices continuously throughout their academic career, and engage students both academically and socially to increase effectiveness in their teaching. 
The process of innovation, as participants reported, necessitates continuous attention to and focus on students, curriculum, and prospective innovative ideas. The Cycle of Innovation subcategory purports two mutual influencers-students and faculty-that continuously and perpetually affect one another to produce pedagogical change. By attending to students and their knowledge base, faculty evaluate students' current understanding and maintain a focus on achieving the learning objectives and curriculum. A Cycle of Innovation intentionally and continuously engages students to assess their learning, thus leading to discovery of opportunities to innovate. Cycle of Innovation, as a continuous process, seeks to engage students to understand what they currently know and yet need to learn to enhance content mastery.

\subsection{Cycle of Innovation}

The Cycle of Innovation, as described by participants, is a continuous process that evaluates learning by intentionally and intuitively measuring students' knowledge and understanding. Kelly described the challenge of bridging knowledge to students, "The challenge, I think, and what I really try to do is really always keep sort of a pulse, always kind of remind myself of the distance that exists between me and them". He further clarified that keeping a pulse on students suggests a continuous process, "It's driven by understanding the process of learning and ways of teaching, and there are better ways of engaging that process and worse ways, and that teaching is constantly trying to improve one's capacity to make those linkages". Kelly's intent to maintain what he called a pulse on students' learning drives him to improve the linkage between what students know and bridge to what they still need to learn. Jordan similarly suggested that innovation is a continuous process to improve student learning. When describing his innovative process, Jordan repeatedly uttered the word "constantly" to convey continuous improvement.

"I think that what you find out is that if you're constantly evaluating, not only in terms of the evaluations but also by having constant contact and interaction with your students, and knowing every student, then you're constantly evaluating. You're constantly-iteratively and incrementally-changing to figure out more about [the] kind of group of humanity, how you get across ideas to your group of humanity". In addition to being abreast of changes in students, Jordan commented on the relational aspect of knowing students and the impact on his teaching. Because students change, Jordan reflected the necessity to change as well the importance of changing pedagogy.

Moreover, to bridge students' knowledge, participants describe the perpetual search for possible ways to innovate to improve learning through sources of inspiration. Regardless of the emphasis on students or curriculum, participants describe the importance of connecting to and engaging in the Cycle of Innovation as it serves as the linchpin to the innovative process. Participants continuously engage in the Cycle of Innovation to improve teaching and learning. 


\subsection{Cycle of Feedback}

To innovate pedagogy, participants partake in a Cycle of Innovation through continuously engaging students and seeking opportunities to modify or adjust teaching and learning. Participants continuously engage in the Cycle of Innovation that stipulates a Cycle of Feedback stemming from engaging with and responding to students to measure their own pedagogical practice. The Cycle of Feedback entails faculty continually gauging students' affect during class. Faculty participants report constantly observing and evaluating students' facial expressions and demeanor within the classroom environment. Next, faculty assess students' comments to determine whether the content is understood or requires further adjustment. Students' remarks and questions reveal depth and breadth of knowledge. Third, when participants interact with students within the scope of the class environment they engage students to discover and assess their grasp of course content. A fourth opportunity for student feedback results in their faculty evaluations at the end of an academic term. Participants conscientiously read faculty evaluations to determine student satisfaction and to determine if further innovation is necessary. Consequently, the Cycle of Feedback provides faculty with a means to evaluate and gauge their success in pedagogical innovation. The Cycle of Feedback, whether students' facial expressions, distracted behaviors, interactions, or formal evaluations, informs participants to prompt and influence the Cycle of Innovation to enhance student learning through pedagogical innovation.

Most participants described specifically how to ascertain student engagement through observing student behaviors closely and interpreting their actions. Morgan specified a few behaviors that help him to evaluate student engagement and the learning process in the classroom environment. "You see students looking at you or leaning forward in their chair or just-you can tell in people's eyes when you're really getting them excited. Oh, yawning. Lack of interest. Picking up the [school newspaper], their newspaper, and reading it. I don't see that very often, but it's pretty clear when a person is getting bored". Although Morgan predominantly determines student engagement through physicality, other participants address student engagement further through relational indicators.

When a participant becomes better acquainted relationally with students, they seem to gauge student affect more effectively, thereby responding successfully to innovative prompts. Jordan detailed his experience with reading students' affect. "But you know I think more important than anything is to have a rapport so that you constantly know what every student is thinking. If you have a small enough class that you can look in their eyes as you're going along... But I think that to me the most important thing is to be able to size up and diagnose each person where they are and to be able to know each one... and there are certain students you just love because for no other reason other than you know their face is going to tell you that you just did excellent". Jordan's description provides an apparent process to evaluate student engagement through rapport by observing their af- 
fect. Although Jordan suggested knowing students as individuals, he innovates to affect students as a collective whole. Essentially, as participants read students' affect to gauge engagement and learning, the observed outcome stimulates the Cycle of Innovation as well as gauges and influences teaching performance.

Apart from student affect, often participants receive student feedback through comments and questions raised during class. Student questions may indicate confusion, basic understanding, or higher-level thinking. Many participants suggested that by listening to and evaluating students' questions as a form of feedback, they can determine students' current knowledge level acquirement. In a sense, questions measure and reveal not only students' comprehension, but also suggest to participants the need to reevaluate their teaching practice, thus prompting innovation.

Kelly, with his large classes, specifies students' questions by suggesting that, "Some questions can appear as erudite, but completely off-point or they're kind of showing off". Other questions he characterizes as students who ask, "any question that they don't know the answer to seems to be a good question". Furthermore, questions, according to Kelly, reveal that students possess, "no understanding, or [their understanding] is completely off-base".

Faculty reported on the importance of students' evaluation and how it affects their work. Most participants specified that evaluations caused them to not only improve their pedagogy, but also to discover ways to engage students more effectively, thereby facilitating innovation. Although many commented on the necessity and importance of thoughtfully considering students' comments, participants also mentioned the possible pain incurred. Rory, a participant who readily solicits student feedback to improve his teaching, commented on the necessity of faculty evaluations and their effect. "We get teaching evaluations here. I used to be able to give straight lectures and get very high teaching evaluations. My guess is, although I can't confirm this, if I were to do that now, I would get much lower teaching evaluations. You know, there's feedback from the students as to what they want and they don't want. It may be hard for them to articulate it, but you can get a sense of what the students are feeling". Rory reads and earnestly considers what students write in his evaluations. He suggested that students' feedback affects his pedagogy to respond to students' needs.

More than one participant suggested not wanting perfect evaluations, believing this means they did not effectively challenge students and their thinking. Jordan reflected on what an informal mentor explained to him, "The same professor's philosophy used to tell us that if your evaluations were perfect, you were really doing something wrong, because you obviously weren't enticing, inciting, and getting students interested, and pushing their pressure points well enough. And it's true with his evaluations... They were usually extremely high, except that every year somebody would hate him because he was so energetic, and he had one personality that was strong in these classes. And you're always going to have somebody react to that. I've always believed that since then, and I've always been a little worried about occasionally perfect evaluations because of that". In 
this example, evaluations guide the participant in gauging the balance between student complacency in learning and the responsibility for participants to challenge academically students. Student evaluations not only assess faculty teaching, but also provide analysis for innovative changes that may be implemented to stimulate student learning.

\subsection{Gradation of Innovation}

Participants engage in the Cycle of Innovation continually by connecting to and associating with students through a Cycle of Feedback to evaluate and assess both knowledge and understanding. Consequently, as participants implement innovation, they gradate changes to improve student comprehension and learning. This Gradation of Innovation consists of three levels-adoption, modification, and creation - that characterize the extent of change in the idea adopted.

Adoption suggests an idea fully accepted without any adjustments or amendments. Participants remark that adoption occurs infrequently because they tend to find an idea, develop, and then adapt it according to their teaching style. A second gradation, modification, consists of innovations most participants implement in this study. Modification includes any adjustment or adaptation of current practices or implementation of new ideas. Third, creation suggests an original idea, concept, or method introduced as a pedagogical innovation. Each gradation may influence the need to innovate moment-by-moment to year-by-year.

Adoption is infrequently used because participants tend to find ideas and adapt them for their own purposes. However, adoption suggests the full usage of an idea from a source apart from the participant. Educational journals, online listservs, and textbook supplements offer many ideas to assist professors in developing pedagogical practices. Rory, an economist, writes textbooks and develops supplementary materials, and finds various sources from an online economic listserv and conferences. He implements changes to keep from being bored and to create memorable experiences for students. As I walked out of his office after our first interview, Rory's parting words were, "If I didn't change things up, I'd go mad"! An adopted idea Rory found on a listserv demonstrated economic principles he was teaching, "What I did was, I cut little [paper] fish, and I'd throw them on the floor, you know, piece of paper, and there's a cheap reward if they grab the fish in the first two minutes, and there's a good reward if they wait two minutes. I explain to them, it pays to wait, and I get as many kids as they want come up to the front of the class, and I've had classes where they tried to collude-they almost make it, but I've never yet had them make it. We discuss how that shows why there's over-fishing".

When referring to the activity, Rory stated, "Well, they'll remember this the rest of their lives". Rory adopted an innovation to effectively teach by engaging students in an activity in which they not only learn the content, but will also remember beyond the scope of his class.

Although participants mentioned innovating pedagogy activity-to-activity, 
they suggested many innovations that occur semester-by-semester. Faculty often try to find contemporary, relevant, and real-world examples to connect knowledge to students' culture. Real-world examples are typically found in media sources. Taylor, a historian, discovered in a small article a several centuries old skeleton found at a crossroads in England, the implication being, the bones were that of an accused witch. Taylor explained, "At first, they weren't sure what they'd found, but it was rapidly established that the skeleton was several centuries old... they established that it was probably the body of a woman executed for witchcraft in 1589. If she'd been executed-they didn't burn them at the stake in England, they hanged them. She'd been buried at the crossroads, rather than in consecrated ground much like a suicide would be buried at the crossroads". Using this example, Taylor engages students' interests with witchcraft and connects to a real-world example. He explained how this real-world example illustrates not only history, but also enhanced student engagement and critical thinking. "We spend the lecture explaining the nature of the sudden preoccupation with witchcraft, which took off in the late 16th century, lasted about 60 years, and then died away. And go through the whole story about why did it happen? What was going on? What the role of all kinds of different factors-legal, social, economic, gender issues; witches nearly always women-not always but nearly always... bring it back to this poor woman who was executed". Although Taylor resembles the traditional college professor with a quiet demeanor, he exudes enthusiasm explaining the academic and educational possibilities of contextualizing students' fascination with a real-world historical example of witchcraft. Innovating through modifying a semester-by-semester example facilitates participants to stay current with students' interests as a method to making knowledge accessible.

Although modification tends to be the largest gradation within innovation and adoption rather infrequently, creation occurs the least. Participants admitted that creation does occur, but also remarked at the rarity; it does not originate from participants. Darcy often views every academically day and common experiences as possible examples for illustrating concepts he tries to demonstrate in class. He described an event almost like an epiphany when he has a moment of creation and recognizes a possible common example to illustrate his content. Darcy elaborated, "I was also standing in the shower and I notice that the water on the wall of the shower runs down and it doesn't run straight down the wall... it's a great illustration of how meandering rivers work. The principle is fundamentally the same, of frictional resistance and so I now take one of my demonstrations, and a squirt bottle and put colored water in it, and a piece of glass, and you make meandering rivers... that's something, I would open it up, you can do this the next time you take a shower, take a look". Darcy's creation moment connects to students' common experience by bridging knowledge to students through discovering an example that makes knowledge accessible.

Darcy's example, albeit elementary and simplistic, captures students' interest. 
Many participants mentioned the importance of gauging students' interest and engagement in the innovative process.

\section{Implication for Practice}

The findings of this qualitative study provide higher education institutions and their faculty that value teaching, in general, and pedagogical innovation, in particular, a framework to support the development of faculty members in their work as teachers. Many colleges and universities indicate a commitment to excellent teaching through teaching and learning centers and faculty development departments. The results of this study suggest that some faculty, regardless of external reward systems, desire to be not only productive researchers, but also excellent teachers by innovating their pedagogical practices to enhance student learning. With intrinsic motivation to innovate pedagogy, faculty transcend the $\mathrm{RU} / \mathrm{VH}$ universities stereotype of research's premier value being exclusive over the values placed on teaching excellence. The implication of this commitment to both research and teaching suggests that faculty who desire to be effective in both domains would benefit from intentional focus on the development of pedagogical innovation to enhance student learning.

Although many colleges and universities do not reward teaching equally as much as research, the importance of effectively teaching students continues to be addressed, researched, and encouraged (Austin, 2002; Bain, 2004; D’Andrea \& Gosling, 2005; Fairweather, 2005). Higher education institutions often offer training-resources, workshops, consultations, and seminars-through teaching and learning centers and faculty development departments, providing tools that support effective teaching; an emphasis on innovative pedagogy to enhance student learning is now better supported; however, the onus to engage in training falls on faculty.

Participants subjectively attributed their peers' lack of teaching skill and pedagogical innovation to three reasons: the focus on the external reward system, the lack of self-awareness needed to innovate, and the paralyzing fear of interacting with students and failing to improve teaching. While little may affect the reward systems for research at colleges and universities, for the purposes of this study, two of these conditions are addressed-self-awareness and fear-as well as suggestions for faculty training programs in the implications for practice. The three domains in which implications for practice would apply are Cycle of Innovation, growth mindset, and emotional intelligence.

The results of this study suggest the importance of understanding and applying an innovative cycle to pedagogical practices to improve student learning. This innovative process, albeit preliminary, provides a concrete framework for those who train faculty in how to improve student learning. Faculty development centers who endeavor to foster the scholarship of teaching and learning may develop interventions for fostering academic and social engagement. Consequently, an aspect of this framework focuses on students' essential contribution to the Cycle of Innovation. Research (Astin, 1997; Pascarella \& Terenzini, 
1998, 2005; Tinto, 1993) has indicated the importance of faculty and student engagement; however, research is limited on how student feedback influences pedagogical innovation. Specifically, faculty development programs often focus on new or emerging pedagogical practices that can be applied to the craft of teaching rather than on responding to input faculty receive from their interactions with students. Training faculty on specific strategies encourages academic and social engagement among students.

Faculty development departments may also prepare faculty to engage in student feedback could include learning to read students' affect, interpreting student questions to assess content comprehension, and reacting appropriately to student responses in their faculty evaluations. The ability to analyze and interpret students' affect is addressed in the section on emotional intelligence. Students' questions reveal various levels of understanding within the classroom environment. The implication for practice suggests that although faculty development programs may focus on training faculty in Socratic questioning to elicit student responses, learning to evaluate their comments and questions using Bloom's Taxonomy (Marzano \& Kendall, 2008) would encourage pedagogical innovations and improve student learning. Pedagogical innovation can be promoted and motivated by accurately assessing what students currently know and understand, discovering the discrepancy between what the faculty member intended to convey, and determining a course of action to bridge the conceptual gap.

In addition to analyzing students' comments and questions, faculty evaluations are another component of improving pedagogical innovation. Participants in this study indicated the importance of reading and responding to faculty evaluations. Some faculty suggested the importance of receiving imperfect teaching evaluations from students to improve their pedagogical practice. If evaluations were perfect, then either they had not challenged students enough or they were not thoughtfully engaging students. Arguably, perfect evaluations would not lead to areas of pedagogical improvement. Consequently, an implication for practice suggests that higher education institutions review faculty evaluation forms considering garnering students' responses to pedagogical innovation. Faculty development departments may develop systems to encourage faculty to reflect on evaluations, explore possible modifications, and integrate changes with current practices. Moreover, institutions should revitalize the emphasis and importance of students being provided the opportunity and sufficient time to thoughtfully and concretely provide feedback on faculty evaluations thoughtfully and concretely.

Another essential contributor to the innovative process is the deconstruction of faculty's internal thinking process. Faculty commented on the importance of remaining open to new ideas, innovating continuously, and accumulating pedagogical improvement over time. Pedagogical innovation requires the fortitude for faculty to avail themselves of revitalized, new, or emerging teaching methods and strategies. A focus on developing a growth mindset among faculty would 
encourage exploration and resiliency. In addition, this suggests that faculty development programs focus on providing ample opportunities for faculty to learning new learning strategies. Time is often a constraint suggesting delivery methods, such as online videos, may be utilized to provide access to faculty. Applying these pedagogical methods suggests an exposure to the necessity to continuously improve current teaching practices continuously, especially as an accumulating process.

An implication for practice is that faculty be taught critical thinking skills in the domain of teaching and pedagogical innovation. Given that faculty who work at higher education institutions are equipped with critical thinking skills, transferring this ability to the domain of pedagogical innovation would lead to more effective teaching. Faculty should be trained in identifying and deconstructing their pedagogical thinking processes, evaluating their current teaching weaknesses, and developing a plan to effectively improve their practice to innovate effectively. Learning to think critically in the domain of teaching would foster pedagogical innovation.

The results of this study suggest that some faculty, regardless of external reward systems, desire not only to be productive researchers, but also to be excellent teachers by innovating their pedagogical practices to enhance student learning. The findings suggest the importance of faculty building on their pedagogical strategies and practices continuously throughout their academic career, and engaging students both academically and socially to increase effectiveness in their teaching.

\section{Conflicts of Interest}

The author declares no conflicts of interest regarding the publication of this paper.

\section{References}

Astin, A. W. (1997). What Matters in College: Four Critical Years Revisited. San Francisco, CA: Jossey-Bass.

Austin, A. E. (2002). Preparing the Next Generation of Faculty: Graduate School as Socialization to the Academic Career. The Journal of Higher Education, 73, 94-122. https://doi.org/10.1080/00221546.2002.11777132

Bain, K. (2004). What the Best College Teachers Do. Cambridge, MA: Harvard University Press.

Blackburn, R. T., \& Lawrence, J. H. (2003). Faculty at Work: Motivation, Expectation, Satisfaction. Baltimore, MD: Johns Hopkins University Press.

Bok, D. (2008). Our Underachieving Colleges: A Candid Look at How Much Students Learn and Why They Should Be Learning More. Princeton, NJ: Princeton University Press. https://doi.org/10.2307/j.ctvcm4jc0

Breslow, L. (2010). Wrestling with Pedagogical Change: The TEAL Initiative at MIT. Change, 42, 23-29. https://doi.org/10.1080/00091383.2010.503173

Capaldi, E. D., Lombardi, J. V., Abbey, C. W., \& Craig, D. D. (2010). The Center for 
Measuring University Performance.

https://mup.umass.edu/sites/default/files/mup-pdf/MUP-Publication-2014-Tracking-A cademic-Research-Funding-The-Competitive-Context-for-the-Last-Ten-Years.pdf

Centra, J. A. (1996). Identifying Exemplary Teachers: Evidence from Colleagues, Administrators, and Alumni. In M. D. Svinicki, \& R. J. Menges (Eds.), Honoring Exemplary Teaching. New Directions for Teaching and Learning (pp. 51-56). San Francisco, CA: Jossey-Bass. https://doi.org/10.1002/tl.37219966510

Charmaz, K. (2014). Constructing Grounded Theory. Los Angeles, CA: Sage Publications.

Creswell, J. W. (2017). Qualitative Inquiry and Research Design: Choosing among Five Approaches (4th ed.). Thousand Oaks, CA: Sage Publications.

D’Andrea, V., \& Gosling, D. (2005). Improving Teaching and Learning: A Whole Institutional Approach. New York: Open University Press.

Fairweather, J. S. (2005). Teaching Salaries; College Faculty; College Instruction; Undergraduate Study; Faculty Publishing; Scholarship; Productivity; Trend Analysis. Journal of Higher Education, 76, 401-422. https://doi.org/10.1353/jhe.2005.0027

Furst-Bowe, J. A., \& Bauer, R. A. (2007). Application of the Baldrige Model for Innovation in Higher Education. New Directions for Higher Education, 137, 5-14. https://doi.org/10.1002/he.242

Kezar, A. J. (2009). Change in Higher Education: Not Enough, or Too Much. Change: The Magazine of Higher Learning, 41, 18-23. https://doi.org/10.1080/00091380903270110

Kontoghiorghes, C., Awbrey, S. M., \& Feurig, P. L. (2005). Examining the Relationship between Learning Organization Characteristics and Change Adaptation, Innovation, and Organizational Performance. Human Resource Development Quarterly, 16, 185-211. https://doi.org/10.1002/hrdq.1133

Kuh, G. D., Kinzie, J., Schuh, J. H., \& Whitt, E. J. (2010). Student Success in College: Creating Conditions That Matter. San Francisco, CA: Jossey-Bass.

Lowman, J. (1996). Characteristics of Exemplary Teachers. In M. D. Svinicki, \& R. J. Menges (Eds.), Honoring Exemplary Teaching. New Directions for Teaching and Learning, No. 65 (pp. 33-40). San Francisco, CA: Jossey-Bass. https://doi.org/10.1002/tl.37219966508

Marzano, R. J., \& Kendall, J. S. (2008). Designing and Assessing Educational Objectives: Applying the New Taxonomy. Thousand Oaks, CA: Sage Publications.

McAlpine, L., \& Harris, R. (2002). Evaluating Teaching Effectiveness and Teaching Improvement: A Language for Institutional Policies and Academic Development Practices. International Journal for Academic Development, 7, 7-17. https://doi.org/10.1080/13601440210156439

Menges, R. J. (1996). Awards to Individuals. In M. D. Svinicki \& R. J. Menges (Eds.), Honoring Exemplary Teaching. New Directions for Teaching and Learning (pp. 3-9). San Francisco, CA: Jossey-Bass. https://doi.org/10.1002/tl.37219966504

Pascarella, E. T., \& Terenzini, P. T. (1998). Studying College Students in the 21st Century: Meeting New Challenges. The Review of Higher Education, 21, 151-165.

Pascarella, E. T., \& Terenzini, P. T. (2005). How College Affects Students: A Third Decade of Research (Vol. 2). San Francisco, CA: Jossey-Bass.

Richards, E. M. (2004). Diffusion of Innovations (5th ed.). New York, NY: Free Press.

Schuster, J. H., \& Finkelstein, M. J. (2008). The American Faculty: The Restructuring of Academic Work and Careers. Baltimore, MD: Johns Hopkins University Press.

Sorcinelli, M. D., \& Davis, B. G. (1996). Honoring Exemplary Teaching in Research Uni- 
versities. In M. D. Svinicki, \& R. J. Menges (Eds.), Honoring Exemplary Teaching. New Directions for Teaching and Learning (pp. 71-76). San Francisco, CA: Jossey-Bass. https://doi.org/10.1002/tl.37219966513

Tinto, V. (1993). Leaving College: Rethinking the Causes and Cures of Student Attrition (2nd ed.). Chicago, IL: University of Chicago Press. https://doi.org/10.7208/chicago/9780226922461.001.0001

Van Note Chism, N. (2006). Teaching Awards: What Do They Award? The Journal of Higher Education, 77, 589-617. https://doi.org/10.1080/00221546.2006.11772308

White, S. C., \& Glickman, T. S. (2007). Innovation in Higher Education: Implications for the Future. New Directions for Higher Education, 137, 97-105. https://doi.org/10.1002/he.248

Zemsky, R. (2009). Making Reform Work: The Case for Transforming American Higher Education. New Brunswick, NJ: Rutgers University Press.

Zhang, J. (2010). Technology-Supported Learning Innovation in Cultural Contexts. Educational Technology Research and Development, 58, 229-243.

https://doi.org/10.1007/s11423-009-9137-6 